\title{
Hereditary polycystic kidney disease: genetic diagnosis and counseling
}

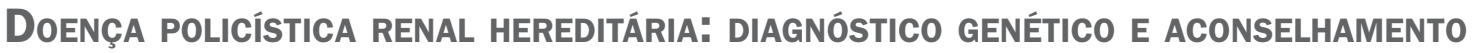 \\ Participants: Martin Whimle; RICardo Simões \\ Sociedade Brasileira de Genética Médica \\ Final preparation: NoveMBER $20^{\mathrm{TH}}, 2012$ \\ Conflict of interest: NoNE
}

\section{DESCRIPTION OF THE EVIDENCE COLLCTION METHOD}

The literature review of scientific articles in this guideline was held in the databases Medline, Cochrane and SciELO. The search for evidence came from actual clinical scenarios and used keywords (MeSH terms) grouped in the following syntax: adult dominant polycystic kidney disease; adult recessive polycystic kidney disease; PKD mutation; PKDH1 mutation; renal cystic disease; polycystin; renal ultrassonography; renal transplantation; fibrocystin; congenital hepatic fibrosis; biliary dysgenesis; liver cystic disease; end-stage renal disease; linkage analysis.

\section{Degree OF RECOMMENDATION AND STRENGTH OF EVIDENCE}

A: Experimental or observational studies of higher consistency.

B: Experimental or observational studies of lower consistency.

C: Case reports (non-controlled studies).

D: Opinions without critical evaluation, based on consensus, physiological studies, or animal models.

Objectives: to present the main scientific information linked to acquired clinical experience and related to diagnosis and genetic counseling in polycystic kidney disease (hereditary).

\section{INTRODUCTION}

The hereditary polycystic kidney disease is defined as autosomal recessive polycystic kidney disease (ARPKD) and autosomal dominant polycystic kidney disease (Adpkd). These two diseases must be distinguished from other hereditary or non-hereditary conditions presenting renal cysts. The hereditary polycystic kidney disease is important because it is relatively common. Adpkd is one of the most common monogenic diseases, with an incidence of 1 in 700 individuals and accounts for $5 \%$ of patients re- quiring hemodialysis or kidney transplantation (B). $.^{2} \mathrm{AR}-$ PKD is rarer, with an incidence of 1 in 20,000 individuals $(\mathbf{B}){ }^{2}$

\section{IN PRENATAL AND NEONATAL CONTEXT, ULTRASONOGRAPHY IS SUFFICIENT TO CONFIRM THE CLINICAL DIAGNOSIS OF ARPKD IN A PATIENT?}

In ARPKD, renal ultrasound abnormalities are detectable from the $20^{\text {th }}$ week of pregnancy, or perhaps from the $13^{\text {th }}$ week of pregnancy when there is an established diagnosis in an affected sibling. However, this applies to $40 \%$ of the affected patients that have a more severe form of the disease. In this subgroup, the ultrasound reveals enlarged bilateral hyperechogenic kidneys, with or without cysts associated with oligohydramnios $(\mathbf{B}){ }^{2}$

Before focusing on this nephropathy, renal tract abnormalities (obstructive cystic dysplasia and multicystic dysplastic kidney) should be excluded. Other hereditary nephropathies (e.g., Bardet-Biedl syndrome) leading to this clinical picture are associated with other anomalies, which set them apart (C). ${ }^{3}$ The most important differential diagnosis is an early presentation of Adpkd. For this reason, it is essential that both parents undergo renal ultrasounds to diagnose the disease. A pregnant woman with fetus affected by Adpkd usually has a normal amniotic fluid volume. Patients in this subgroup (40\%) develop Potter sequence and die of respiratory failure shortly after birth. Other patients affected with milder ARPKD (60\%) do not show conclusive ultrasound signs and can survive for more than three decades.

\section{Recommendation}

Ultrasonography is the first investigation applied in fetuses and neonates with suspected ARPKD. In addition, enlarged and hyperechoic kidneys are common findings on routine ultrasound examinations in this context. It is essential, subsequently, to assess the patient's family back- 
ground. In the absence of other malformations, the main diagnosis remains ARPKD or Adpkd.

\section{IN PRENATAL AND NEONATAL CONTEXT, IF THE RESULT OF THE ULTRASOUND IS INCONCLUSIVE, DOES HISTOPATHOLOGY ALLOW TO REACH A DEFINITIVE CONCLUSION?}

Pathological examinations performed during autopsy in patients affected with severe nephropathy (subgroup of $40 \%$ ) confirmed the diagnosis of ARPKD (C) (D). ${ }^{4,5}$ Dilation and hyperplasia of collecting duct are observed, which may appear cystic, without involvement of the nephron.

ARPKD invariably occurs with biliary dysgenesis (B) (D). ${ }^{5,6}$ The intrahepatic bile ducts dilate and increase in number with subsequent development of periportal fibrosis. This clinical picture, called congenital hepatic fibrosis, is essential for the diagnosis of ARPKD, even though it is not a pathognomonic sign. Portal hypertension is a common sequel, which evidence can be obtained through ultrasonography.

In patients affected with milder ARPKD (the subgroup of $60 \%$ ), the clinical course is variable and signs of portal hypertension may prevail. Liver biopsy should therefore be considered in these cases $(\mathbf{C}){ }^{7,8}$

\section{Recommendation}

It is essential to try to establish the diagnosis using anatomopathological examination when the ultrasound is not informative to allow genetic counseling.

\section{IN THE CONTEXT OF A YOUNG ADULT, THE ULTRASOUND EXAMINATION IS SUFFICIENT TO CONFIRM THE CLINICAL DIAGNOSIS OF ARPKD IN A PATIENT?}

Patients affected with ARPKD who survive to (and throughout) adolescence tend to develop primarily liver and biliary impairment with less renal involvement. Hepatosplenomegaly, portal hypertension and Caroli disease, in the presence of systemic hypertension and renal failure, serve to confirm the diagnosis $(\mathbf{C}) .{ }^{9}$ In these cases, the kidney may be reduced in size $(\mathbf{C}) .{ }^{10}$

\section{Recommendation}

The signs listed can establish the diagnosis. When inconsistencies among clinical signs persist, the anatomopathological examination by means of liver biopsy should be performed.

\section{IN THE CONTEXT OF AN ADULT, IF THE RESULT OF THE ULTRASOUND EXAMINATION IS INCONCLUSIVE, DOES THE MOLECULAR TEST ALLOW TO REACH A DEFINITIVE CONCLUSION?}

Molecular tests can be direct (such as gene sequencing PKHD1) or indirect, using linkage analysis (C) ${ }^{11}$ which depends on the possibility of analyzing a minimum number of family members known to be affected and unaffected - which is not always feasible. Direct molecular genetic tests cannot detect all mutations causing ARPKD, so that the detection rate is around $80 \%$ or less when the disease is milder $(\mathbf{C}){ }^{12,13}$ Occasionally, the patient may inherit two low penetrance mutations (hypomorphic) in both copies of the PKD1 (or PKD2) gene, thus showing a phenotype that is very similar to neonatal ARPKD, which makes the molecular test even more necessary $(\mathbf{C}) \cdot{ }^{14}$

\section{Recommendation}

Despite its limitations, molecular tests can be performed to try to confirm the diagnosis and to document at least one of the disease-causing mutations. The type and position of mutations in the PKHD1 gene provide information about the prognosis of the disease $(\mathbf{C}){ }^{15}$

\section{What IS The ROLE OF MOLECULAR TESTING FOR GENETIC COUNSELING OF A COUPLE OR A FAMILY TRANSMITTING ARPKD?}

Molecular tests are the only ones able to provide predictive information about ARPKD in individuals before the clinical signs and symptoms develop. In some families, the disease has a different progression among affected siblings and molecular test can determine if a brother with mild signs is affected or not (C) ${ }^{8,15}$ Since a high percentage of individuals affected with ARPKD survive until (and throughout) adolescence, molecular tests allow to identify them prior to onset of symptoms. In these individuals, the verification of the effects of hypertension and portal hypertension enables treatment, prolonging life $(\mathbf{C}) .{ }^{16}$

\section{Recommendation}

Pre-test counseling is required to explain the implications of the results that will be obtained in the tests and to clarify the limitations inherent to the method. After proper consideration, family members are tested, with continued post-test counseling. A couple transmitting ARPKD that wants to prevent the disease in future children needs to perform these tests, anticipating their application in prenatal or preim- 
plantation studies $(\mathbf{C}) .^{7}$ Direct analysis of the PKHD1 gene should be performed in the parents of the affected patient when there is no material of this individual.

\section{IS ULTRASOUND EXAMINATION USED TO CONFIRM THE CLINICAL DIAGNOSIS OF ADPKD?}

There are consensual criteria for establishing the diagnosis in patients suspected of Adpkd. The greatest difficulty is to make the diagnosis in patients younger than 30 years and without a family history of the disease, since the formation of renal cysts depends on the age, and the disease may be caused by new mutations in up to $15 \%$ of cases (C). ${ }^{17}$

In patients suspected of Adpkd, the presence of renal cysts on ultrasonography allows the diagnosis, depending on the age $(\mathbf{B})$, of: ${ }^{18,19}$

- patients aged 15 to 29 years, with 3 or more unilateral or bilateral cysts (sensitivity 0.695 , specificity 1 ; positive predictive value of 1 , and a negative predictive value of 0.780 ), with a likelihood ratio of 3.27 ;

- patients aged between 40 and 59 years, with two or more unilateral or bilateral cysts (sensitivity 1 , specificity of 0.978 ; positive predictive value of 0.972 , and negative predictive value of 1 );

- patients aged 60 years or older, with 4 or more cysts in each kidney (sensitivity of 1 and specificity of 1 ).

The criteria are different when the goal is to exclude potential kidney donors, in transplants, as described below.

\section{Recommendation}

An assessment by ultrasound is recommended as first investigation in all patients suspected of Adpkd to try to establish the diagnosis according to the listed criteria.

\section{Does MAGNetic RESONANCE IMAGING ADD INFORMATION TO THE ULTRASOUND EXAMINATION TO IMPROVE THE CLINICAL DIAGNOSIS OF A PATIENT WITH ADPKD?}

When the result of the ultrasound is inconclusive, MRI, being more sensitive, can provide additional information. However, MRI also detects small simple cysts (without consequence), which have their number and size increase with age, and its role in this context has not been formally evaluated $(\mathbf{C}){ }^{20}$

Recommendation
MRI should not be used as first-choice imaging test for the diagnosis of Adpkd.

\section{Which ULtRAsOUND AND MRI TEST RESULTS INDICATE SUBSEQUENT USE OF MOLECULAR TESTS TO INDICATE ADPKD?}

Individuals under 30 years old and at risk of being affected with Adpkd, with less than 3 renal cysts on ultrasound, can be carriers of a mutated gene. Furthermore, up to $15 \%$ of affected individuals have no family history of the disease, and may or may not show abnormalities on imaging studies $(\mathbf{C}) \cdot{ }^{17}$ Mutations in the PKD1 gene cause a more severe disease with early development of renal failure and less survival than mutations in the PKD2 gene (mean age 53 years for PKD1 versus 69.1 for PKD2 versus 78 years for controls) (B). ${ }^{21}$ However, the molecular tests are capable of identifying close to $85 \%$ of all disease-causing mutations (in both genes, PKD1 [85\% of cases] and PKD2 [15\% of cases]), and several molecular variants found are still difficult to categorize as pathogenic or nonpathogenic $(\mathbf{B})(\mathbf{C}) .^{22-24}$

Recommendation

Molecular tests should be applied to individuals under 30 years of age, at risk of being affected with Adpkd and with less than 3 renal cysts on ultrasound. These tests should also be considered in patients with no family history of the disease, but with atypical image results or mild kidney disease or with atypical extrarenal signs of Adpkd, since other inherited diseases can present similar phenotypes, such as autosomal dominant polycystic liver disease, as well as other acquired diseases (C) (D)..$^{25,26}$

\section{What ARE THE ADVANTAGES AND DISADVANTAGES OF INDIRECT APPROACHES (LINKAGE ANALYSIS) VERSUS DIRECT APPROACHES IN MOLECULAR TESTING FOR ADPKD?}

Genetic linkage analysis with polymorphic markers within and/or near genes and which define haplotypes, complements the direct tests, and gene sequencing is the most direct of them $(\mathbf{C}) .{ }^{24}$ The haplotype analysis is quick, simple and low cost, but depends on the possibility of analyzing a minimum number of relatives knowingly affected and unaffected within a family, which is not always possible.

Even so, occasionally, the markers are not sufficiently informative in some families. Direct studies can be made in a single patient, but are costly, time consuming and expensive, and not always provide definitive infor- 
mation (D). ${ }^{26}$ Few centers are able to conduct the full direct studies.

\section{Recommendation}

The use of several tests must be decided considering the inquirer and the family concerned. A proper heredogram is essential and the availability of family members to participate in the counseling and testing is crucial for performing haplotype analysis.

\section{WHAT IS THE ROLE OF MOLECULAR TESTING FOR GENETIC COUNSELING OF A COUPLE OR A FAMILY TRANSMITTING ADPKD?}

Molecular tests are the only ones able to provide predictive information about Adpkd in individuals before the clinical signs and symptoms develop. In some families, the disease develops differently among affected siblings and molecular tests can define whether a sibling with different signs is affected or not $(\mathbf{B})(\mathbf{C}) .^{27,28}$ The type and position of mutations in the genes provide information on disease prognosis $(\mathbf{C}) .{ }^{28-30}$ The characteristics of the clinical course of the disease in the family allow to predict which of the genes, PKD1 or PKD2, is probably the cause of the disease $(\mathbf{C}) .{ }^{31}$ Gene rearrangements make up around $4 \%$ of the molecular lesions, which, together with the occurrence of mosaicism, complicates the molecular analysis $(\mathbf{B})(\mathbf{C}){ }^{32,33}$

\section{Recommendation}

Pre-test counseling is needed to clarify the implications of the results to be obtained and to enumerate inherent limitations. After proper consideration, family members are tested, with continued post-test counseling. A couple of Adpkd carriers wishing to prevent their future children from being affected must undergo these tests, anticipating their application in studies prenatal or preimplantation (C). ${ }^{34}$ Tests should also be considered in families transmitting the polycystic kidneys disease with early onset, or to provide a prognosis when there is no other family member to compare $(\mathbf{D}){ }^{35}$

It is important to note that in these guidelines molecular technologies evolve quickly. So, constantly, sensitivity, ease of implementation and thus cost-effectiveness are affected.

\section{Does a close relative of an AFFeCted PATIENT WITH ADPKD (WHO IS CLINICALLY NORMAL AND A CANDIDATE FOR KIDNEY DONATION) HAVE TO PERFORM MOLECULAR EXAMINATION IN A PRETRANSPLANT CONTEXT?}

For donors under 30 years of age, imaging studies are not adequate to exclude the presence of disease, and the same applies if these tests are inconclusive; in these cases, molecular tests are indicated (B). ${ }^{19}$ If the donor is part of a family well studied in relation to Adpkd, linkage studies are likely to be sufficient to conclude whether he or she has PKD1 or PKD2 mutated. Otherwise, direct studies will be needed, with exceptions already presented.

\section{Recommendation}

In this context, molecular tests are required for donors younger than 30 years (B). ${ }^{19}$ In the absence of renal cysts and being the donor affected, it is likely that mutations in PKD2 gene are responsible for disease.

\section{References}

1. Iglesias CG, Torres VE, Offord KP, Holley KE, Beard CM, Kurland LT Epidemiology of adult polycystic kidney disease, Olmsted County, Minnesota: 1935-1980. Am J Kidney Dis 1983; 6:630-9.

2. Zerres K, Mücher G, Becker J, Steinkamm C, Rudnik-Schöneborn S, Heikkilä $\mathrm{P}$ et al. Prenatal diagnosis of autosomal recessive polycystic kidney disease (ARPKD): molecular genetics, clinical experience, and fetal morphology. Am J Med Genet 1998; 76:137-44.

3. Chaumoitre K, Brun M, Cassart M, Maugey-Laulom B, Eurin D, Didier F et al. Differential diagnosis of fetal hyperechogenic cystic kidneys unrelated to renal tract anomalies: a multicenter study. Ultrasound Obstet Gynecol 2006; 28:911-7.

4. Blythe $\mathrm{H}$, Ockenden B. Polycystic disease of the kidneys and liver presenting in childhood. J Med Genet 1971; 8:257-84

5. Lonergan GJ, Rice RR, Suarez ES. Autosomal recessive polycystic kidney disease: radiologic-pathologic correlation. Radiographics 2000; 20:837-55.

6. Guay-Woodford LM, Desmond RA. Autosomal recessive polycystic kidney disease: the clinical experience in North America. Pediatrics 2003; 111:1072-80.

7. Zerres K, Senderek J, Rudnik-Schöneborn S, Eggermann T, Kunze J, Mononen $\mathrm{T}$ et al. New options for prenatal diagnosis in autosomal recessive polycystic kidney disease by mutation analysis of the PKHD1 gene. Clin Genet 2004; 66:53-7.

8. Bergmann C, Senderek J, Windelen E, Küpper F, Middeldorf I, Schneider F, et al. Clinical consequences of PKHD1 mutations in 164 patients with autosomal-recessive polycystic kidney disease (ARPKD). Kidney Int 2005; 67:829-48.

9. Adeva M, El-Youssef M, Rossetti S, Kamath PS, Kubly V, Consugar MB et al Clinical and molecular characterization defines a broadened spectrum of autosomal recessive polycystic kidney disease (ARPKD). Medicine 2006; 85:1-21.

10. Blickman JG, Bramson RT, Herrin JT. Autosomal recessive polycystic kidney disease: long-term sonographic findings in patients surviving the neonatal period. Am J Roentgenol 1995; 5:1247-50.

11. Consugar MB, Anderson SA, Rossetti S, Pankratz VS, Ward CJ, Torra R et al. Haplotypeanalysis improves molecular diagnostics of autosomal recessive polycystic kidney disease. Am J Kidney Dis 2005; 45:77-87. 
12. Rossetti S, Torra R, Coto E, Consugar M, Kubly V, Málaga S et al. A complete mutation screen of PKHD1 in autosomal-recessive polycystic kidney disease (ARPKD) pedigrees. Kidney Int 2003; 64:391-403.

13. Sharp AM, Messiaen LM, Page G, Antignac C, Gubler MC, Onuchic LF etal Comprehensive genomic analysis of PKHD1 mutations in ARPKD cohorts. J Med Genet 2005; 42:336-49.

14. Vujic M, Heyer CM, Ars E, Hopp K, Markoff A, Örndal C et al. Incompletely penetrant PKD1 alleles mimic the renal manifestations of ARPKD. J Am Soc Nephrol 2010; 21:1097-102.

15. Furu L, Onuchic LF, Gharavi A, Hou X, Esquivel EL, Nagasawa Y et al Milderpresentation of recessive polycystic kidney disease requires presence of amino acid substitution mutations. J Am Soc Nephrol 2003; 14:2004-14

16. Roy S, Dillon MJ, Trompeter RS, Barratt TM. Autosomal recessive polycystic kidney disease: long-term outcome of neonatal survivors. Pediatr Nephrol 1997; 11:302-6.

17. Reed B, McFann K, Kimberling WJ, Pei Y, Gabow PA, Christopher K et al Presence of de novo mutations in autosomal dominant polycystic kidney disease patients without family history. Am J Kidney Dis 2008; 52:1042-50.

18. Nicolau C, Torra, R, Badenas C, Vilana R, Bianchi L, Gilabert R et al Autosomal dominant polycystic kidney disease types 1 and 2: assessment of US sensitivity for diagnosis. Radiology 1999; 21:273-6.

19. Pei Y, Obaji J, Dupuis A, Paterson AD, Magistroni R, Dicks E et al. Unified criteria for ultrasonographic diagnosis of Adpkd. J Am Soc Nephrol 2009; 20:205-12.

20. Nascimento AB, Mitchell DG, Zhang XM, Kamishima T, Parker L, Holland GA. Rapid MR imaging detection of renal cysts: age-based standards. Radiology 2001; 221:628-32.

21. Hateboer N, van Dijk MA, Bogdanova N, Coto E, Saggar-Malik AK, San Millan JL et al. Comparison of phenotypes ofpolycystic kidney disease types 1 and 2. European PKD1-PKD2 Study Group. Lancet 1999; 353:103-7.

22. Garcia-Gonzalez MA, Jones JG, Allen SK, Palatucci CM, Batish SD, Seltzer WK et al. Evaluating the clinical utility of a molecular genetic test for polycystic kidney disease. Mol Genet Metab 2007; 92:160-7.

23. Rossetti S, Consugar MB, Chapman AB, Torres VE, Guay-Woodford LM, Grantham JJ et al. Comprehensive molecular diagnostics in autosomal dominant polycystic kidney disease. J Am Soc Nephrol 2007; $18: 2143-60$
24. Zhao X, Paterson AD, Zahirieh A, He N, Wang K, Pei Y. Molecular diagnosticsin autosomal dominant polycystic kidney disease: utility and limitations. Clin J Am Soc Nephrol 2008; 3:146-52.

25. Pei Y. Diagnostic approach in autosomal dominant polycystic kidney disease. Clin J Am Soc Nephrol 2006;1:1108-14.

26. Hoevenaren IA, Wester R, Schrier RW, McFann K, Doctor RB, Drenth JP et al. Polycystic liver: clinical characteristics of patients with isolated polycystic liver disease compared with patients with polycystic liver and autosomal dominant polycystic kidney disease. Liver Int 2008; 28:264-70.

27. Rossetti S, Burton S, Strmecki L, Pond GR, San Millán JL, Zerres K et al. The position of the polycystic kidney disease 1 (PKD1) gene mutation correlates with the severity of renal disease. J Am Soc Nephrol 2002; 13:1230-7.

28. Paterson AD, Magistroni R, He N, Wang K, Johnson A, Fain PR et al. Progressive loss of renal function is an age-dependent heritable trait in type 1 autosomal dominant polycystic kidney disease. J Am Soc Nephrol 2005; 16:755-62

29. Hateboer N, Veldhuisen B, Peters D, Breuning MH, San-Millán NJL, Bogdanova $\mathrm{N}$ et al. Location of mutations within the PKD2 gene influences clinical outcome. Kidney International 2000; 57:1444-51.

30. Magistroni R, He N, Wang K, Andrew R, Johnson A, Gabow P et al. Genotyperenal function correlation in type 2 autosomal dominant polycystic kidney disease. J Am Soc Nephrol 2003; 14:1164-74.

31. Barua M, Cil O, Paterson AD, Wang K, He N, Dicks E et al. Family history of renal disease severity predicts the mutated gene in Adpkd. J Am Soc Nephrol 2009; 20:1833-8.

32. Consugar MB, Wong WC, Lundquist PA, Rossetti S, Kubly VJ, Walker DL et al. Characterization of large rearrangements in autosomal dominant polycystic kidney disease and the PKD1/TSC2 contiguous gene syndrome. Kidney Int 2008; 74:1468-79.

33. Connor A, Lunt PW, Dolling C, Patel Y, Meredith AL, Gardner A, Hamilton NK et al. Mosaicism in autosomal dominant polycystic kidney disease revealed by genetic testing to enable living related renal transplantation. Am J Transplantation 2008; 8:232-7.

34. De Rycke M, Georgiou I, Sermon K, Lissens W, Henderix P, Joris H et al PGD for autosomal dominant polycystic kidney disease type 1. Molecular Human Reproduction 2004; 11:65-71.

35. Harris PC, Rossetti S. Molecular diagnostics for autosomal dominant polycystic kidney disease. Nat Rev Nephrol 2010; 6:197-206. 